\title{
Learning approach among health sciences students in a medical college in Nepal: a cross-sectional study
}

This article was published in the following Dove Press journal:

Advances in Medical Education and Practice

4 March 2016

Number of times this article has been viewed

\section{Dev Kumar Shah \\ Ram Lochan Yadav \\ Deepak Sharma \\ Prakash Kumar Yadav \\ Niraj Khatri Sapkota \\ Rajesh Kumar Jha \\ Md Nazrul Islam}

Department of Physiology, Chitwan Medical College, Bharatpur, Chitwan, Nepal

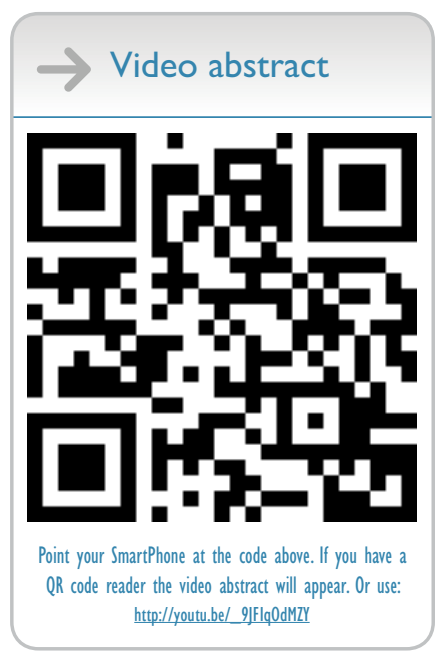

Correspondence: Dev Kumar Shah Department of Physiology, Chitwan Medical College, Bharatpur-10, Chitwan 44200, Nepal

Tel +97798041 I 0643

Fax +97756532937

Email devshahdr@yahoo.com
Background: Many factors shape the quality of learning. The intrinsically motivated students adopt a deep approach to learning, while students who fear failure in assessments adopt a surface approach to learning. In the area of health science education in Nepal, there is still a lack of studies on learning approach that can be used to transform the students to become better learners and improve the effectiveness of teaching. Therefore, we aimed to explore the learning approaches among medical, dental, and nursing students of Chitwan Medical College, Nepal using Biggs's Revised Two-Factor Study Process Questionnaire (R-SPQ-2F) after testing its reliability.

Methods: R-SPQ-2F containing 20 items represented two main scales of learning approaches, deep and surface, with four subscales: deep motive, deep strategy, surface motive, and surface strategy. Each subscale had five items and each item was rated on a 5-point Likert scale. The data were analyzed using Student's $t$-test and analysis of variance. Reliability of the administered questionnaire was checked using Cronbach's alpha.

Results: The Cronbach's alpha value (0.6) for 20 items of R-SPQ-2F was found to be acceptable for its use. The participants predominantly had a deep approach to learning regardless of their age and sex (deep: $32.62 \pm 6.33$ versus surface: $25.14 \pm 6.81, P<0.001$ ). The level of deep approach among medical students $(33.26 \pm 6.40)$ was significantly higher than among dental (31.71 \pm 6.51$)$ and nursing (31.36 \pm 4.72$)$ students. In comparison to first-year students, deep approach among second-year medical $(34.63 \pm 6.51$ to $31.73 \pm 5.93 ; P<0.001)$ and dental (33.47 \pm 6.73 to $29.09 \pm 5.62 ; P=0.002$ ) students was found to be significantly decreased. On the other hand, surface approach significantly increased $(25.55 \pm 8.19$ to $29.34 \pm 6.25 ; P=0.023$ ) among second-year dental students compared to first-year dental students.

Conclusion: Medical students were found to adopt a deeper approach to learning than dental and nursing students. However, irrespective of disciplines and personal characteristics of participants, the primarily deep learning approach was found to be shifting progressively toward a surface approach after completion of an academic year, which should be avoided.

Keywords: deep, surface, motive, strategy

\section{Introduction}

The nature of the relationship between student, context, and task is described by an approach to learning. The aptitude and motivation of individual students and their own approaches to learning, the quality and diversity of the student body, the curriculum they study, the caliber and strategies of teachers, the size and nature of their classes, assessment processes and feedback, availability and use of the learning resources (such as libraries, laboratories, and information technology), the learning environment of classroom, residence, 
and extracurricular settings along with wider institutional and social context influence the quality of learning. ${ }^{1}$

Deep and surface are two different approaches the students adopt for learning. The students who are motivated by an interest in the subject material and/or recognize its professional application adopt the deep approach. On the other hand, the students who are predominantly motivated either by a desire to complete the course or a fear of failure adopt the surface approach to learning. Deep learners critically analyze new ideas and link them to already known concepts and principles, this leads to understanding and long-term retention of concepts and can be used to solve the novel problems in unfamiliar contexts. ${ }^{2}$ Surface learners remain focused on reproducing and memorizing the information they believe important for assessment rather than for understanding, which leads to superficial retention of knowledge and information. ${ }^{3}$

The generic aim of good teaching is to encourage students to adopt a deep approach and to discourage the use of a surface approach. ${ }^{4}$ The mean of the approaches of the students in a class gives an index of the quality of the teaching in that class. However, when teaching and assessment methods are not aligned to the aims of teaching the subject, they often encourage a surface approach. Measuring students' approaches to learning can be useful to help the students to become better learners, to assist individual academics who are concerned in monitoring and improving the effectiveness of their teaching, and also to identify the students at risk because of ineffective strategies. ${ }^{5,6}$

Subasinghe and Wanniachchi ${ }^{7}$ found the most frequent approach adopted by medical students of Faculty of Medicine, Colombo, was a deep approach, while another study done by Samarakoon et $\mathrm{al}^{8}$ found that the predominant approach to learning was surface approach among medical students of the University of Colombo. A study conducted on Pakistani students in tertiary institutions has shown that the students predominantly have higher scores on deep approach, but this differs significantly for various fields of study. ${ }^{9}$ The learning approaches of Nepalese health sciences students have not been documented so far. We planned this study to explore the learning approaches among medical, dental, and nursing students of Chitwan Medical College (CMC), Nepal, using Biggs's Revised Two-Factor Study Process Questionnaire (R-SPQ-2F) after testing its psychometric properties for use. The outcome of the study was intended to be used on the broad aspect for the benefit of students and academicians.

\section{Methods}

This observational descriptive cross-sectional study was carried out at CMC affiliated to Tribhuvan University, Bharatpur,
Nepal. The study population included all undergraduate students of first- and second-year MBBS (bachelor of medicine, bachelor of surgery) and BDS (bachelor of dental surgery) programs and the first-year nursing program of CMC. The study was conducted in the 2015 academic year.

Ethical clearance was obtained from the institutional review committee of $\mathrm{CMC}$ and informed verbal consent was obtained from the participants. The consenting students were invited to participate in the study and briefed about the objectives of the study, and confidentiality of responses was ensured by maintaining anonymity of responders.

Data collection was carried out during lectures and practical sessions via a self-administered 20 -items questionnaire, R-SPQ-2F, to evaluate the study approach of the students. ${ }^{4}$ Preference for the R-SPQ-2F was due to its good reliability coefficients and goodness of fit as indicated by various research. ${ }^{4,9-11}$

Ten items of the questionnaire were related to each of deep and surface approach to study separately. Out of ten items each for deep and surface approach, five items reflect the motives (which refers to why students learn) and next five items reflect the strategy (which refers to how they learn) adopted by the students for their study approach (deep/surface).

The students were asked to rate the statements using a 5 -point Likert scale where 1 - never or only rarely true of me; 2 - sometimes true of me; 3 - true for me about half the time; 4 - frequently true for me; and 5 - always or almost always true for me.

The responses to the questionnaire were analyzed according to the scoring system provided by Biggs.

- Deep approach score: $\Sigma$ All deep motive scores + all deep strategy scores.

- Surface approach score: $\Sigma$ All surface motive scores + all surface strategy scores.

The questionnaire was piloted with 45 undergraduate first-year medical students to ensure unambiguity of the questions. Following the pilot study, the test was administered on a wider scale.

Data were computerized and analyzed using Statistical Package of Social Sciences (SPSS) version-20 (IBM Corporation, Armonk, NY, USA). Frequency distribution, independent sample $t$-test, and analysis of variance (ANOVA) were used wherever necessary. Reliability of administered questionnaire was checked by Cronbach's alpha.

\section{Result}

A total of 410 questionnaires were distributed, 372 of which were completed and returned, giving an overall response rate of $90.7 \%$. The mean age of the respondents was $19.8 \pm 1.3$ years. 
Among 372 respondents, 201 were male and 171 were female. Thirty-six out of 372 MBBS and BDS students were awarded scholarships by Ministry of Education of Nepal. The MBBS students (first year $=134$; second year $=120$ ) constituted $68.27 \%$ of the sample; BDS students (first year $=38$; second year $=42$ ) $21.5 \%$; and nursing students $10.21 \%$.

In our study population, R-SPQ-2F had overall Cronbach's alpha value of 0.6 for its 20 items. The deep and surface approach total scales were found to have Cronbach's alphas of 0.71 and 0.72 , respectively, and the brief R-SPQ-2F motive and strategy subscales are listed in Table 1.

Table 2 lists the correlations between scales and subscales of the R-SPQ-2F. There was a statistically significant positive relationship between main scale (deep/surface approach) and its subscales (motive and strategy). However, the deep approach and its subscales were negatively correlated with surface approach and its subscales.

The study approach of the participants and their associated motive and strategy are shown in Figure 1. The overall mean value of deep approach (32.62 \pm 6.33$)$ was found to be significantly greater $(P<0.001)$ than surface approach (25.14 \pm 6.81$)$ among all the participants.

Means and standard deviations of the R-SPQ-2F measures among the students of different program of study and their comparisons are reported in Table 3. The result showed the significant differences in deep and surface approach to study, $P=0.012$ and $P<0.001$, respectively, between medical and dental students. The mean value of medical students for deep approach and dental students for surface approach was found to be higher. On comparisons among motive and strategy subscales of study approach between medical and dental students, significant differences were found in all subscales except on deep strategy. Similar results were obtained on comparison between medical and nursing students. The significant differences were noticed on deep approach $(P=0.032)$ and deep motive $(P=0.015)$ between medical and nursing students, and on both scales the mean values of medical students were greater than nursing students. However, no significant difference on any scales of study approach was found between dental and nursing students.

Table I Reliability test of questionnaire

\begin{tabular}{ll}
\hline Subscales & Cronbach's alpha value \\
\hline Deep approach & 0.71 \\
Deep motive & 0.56 \\
Deep strategy & 0.56 \\
Surface approach & 0.72 \\
Surface motive & 0.62 \\
Surface strategy & 0.48 \\
Total & 0.60 \\
\hline
\end{tabular}

Table 2 Pearson correlations between scales and subscales of the Revised Two-factor Study Process Questionnaire

\begin{tabular}{|c|c|c|c|c|c|c|}
\hline Variable & $\begin{array}{l}\text { Deep } \\
\text { approach }\end{array}$ & $\begin{array}{l}\text { Deep } \\
\text { motive }\end{array}$ & $\begin{array}{l}\text { Deep } \\
\text { strategy }\end{array}$ & $\begin{array}{l}\text { Surface } \\
\text { approach }\end{array}$ & $\begin{array}{l}\text { Surface } \\
\text { motive }\end{array}$ & $\begin{array}{l}\text { Surface } \\
\text { strategy }\end{array}$ \\
\hline $\begin{array}{l}\text { Deep } \\
\text { approach }\end{array}$ & I & $0.876^{*}$ & $0.882 *$ & $-0.192 *$ & $-0.233^{*}$ & $-0.107^{* *}$ \\
\hline $\begin{array}{l}\text { Deep } \\
\text { motive }\end{array}$ & $0.876^{*}$ & 1 & $0.545^{*}$ & $-0.186 *$ & $-0.235^{*}$ & -0.093 \\
\hline $\begin{array}{l}\text { Deep } \\
\text { strategy }\end{array}$ & $0.882^{*}$ & $0.545^{*}$ & I & $-0.153 *$ & $-0.176 *$ & -0.096 \\
\hline $\begin{array}{l}\text { Surface } \\
\text { approach }\end{array}$ & $-0.192^{*}$ & $-0.186 *$ & $-0.153 *$ & I & $0.902 *$ & $0.890 *$ \\
\hline $\begin{array}{l}\text { Surface } \\
\text { motive }\end{array}$ & $-0.233^{*}$ & $-0.235^{*}$ & $-0.176 *$ & $0.902^{*}$ & I & $0.605^{*}$ \\
\hline $\begin{array}{l}\text { Surface } \\
\text { strategy }\end{array}$ & $-0.107 * *$ & -0.093 & -0.096 & $0.890 *$ & $0.605 *$ & 1 \\
\hline
\end{tabular}

Notes: *Correlation is significant at the 0.01 level (two-tailed). **Correlation is significant at the 0.05 level (two-tailed).

When study approach of first- and second-year participants was compared, significant difference was observed on deep approach $(P<0.001)$ and its motive and strategy subscales ( $P=0.005$ and $P<0.001$, respectively) among medical students (Table 4). There was significant differences on deep approach $(P=0.002)$, surface approach $(P=0.023)$, deep motive $(P<0.001)$, and surface motive $(P=0.004)$ among first- and second-year dental students (Table 4).

To explore the differences in mean score of different study approach, multiple comparisons (ANOVA) among MBBS, BDS, and nursing students were done and are listed in Table 5. To identify these differences, Tukey HSD and Bonferroni procedures were used. Both the procedures revealed the significant differences between MBBS and BDS students on all parameters of study approach other than deep strategy. Significant difference was also observed in deep motive of nursing students in comparison to medical students. However, no significant difference was shown by these procedures between nursing and dental students using this study approach.

No significant difference was found when the scores of self-funded and scholarship-awarded students were

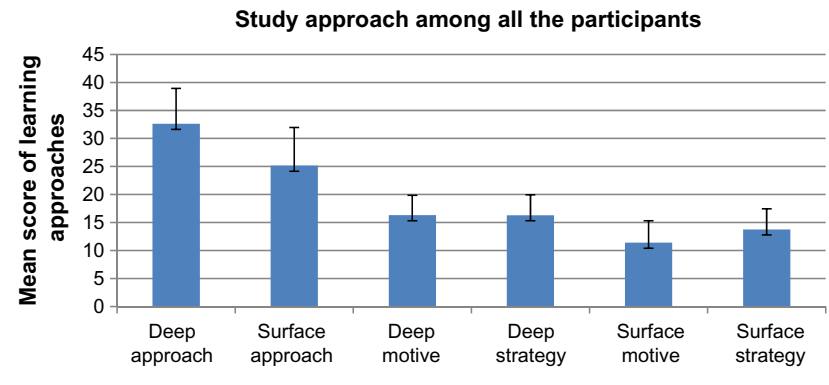

Figure I Mean \pm standard deviation of deep and surface study approach including their motive and strategy among all participants.

Note: These are mean scores out of a possible score of 50 for deep and surface approach and out of a possible score of 25 for motive and strategy subscales. 
Table 3 Comparison of the R-SPQ-2F measures between MBBS, BDS, and nursing students on study approach

\begin{tabular}{lllllll}
\hline Variable & $\begin{array}{l}\text { MBBS, } \\
\text { mean } \pm \text { SD }\end{array}$ & $\begin{array}{l}\text { BDS, } \\
\text { mean } \pm \text { SD }\end{array}$ & $\begin{array}{l}\text { Nursing, } \\
\text { mean } \pm \text { SD }\end{array}$ & $\begin{array}{l}\text { PI value } \\
\text { (MBBS vs BDS) }\end{array}$ & $\begin{array}{l}\text { P2 value } \\
\text { (MBBS vs nursing) }\end{array}$ & $\begin{array}{l}\text { P3 value } \\
\text { (BDS vs nursing) }\end{array}$ \\
\hline Deep approach & $33.26 \pm 6.40$ & $31.7 I \pm 6.51$ & $31.36 \pm 4.72$ & $\mathbf{0 . 0 1 2}$ & $\mathbf{0 . 0 3 2}$ & 0.870 \\
Surface approach & $24.25 \pm 6.55$ & $27.5 I \pm 7.45$ & $26.15 \pm 5.89$ & $<\mathbf{0 . 0 0 I}$ & 0.093 & 0.326 \\
Deep motive & $16.73 \pm 3.54$ & $15.46 \pm 3.65$ & $15.26 \pm 2.92$ & $\mathbf{0 . 0 0 6}$ & $\mathbf{0 . 0 1 5}$ & 0.769 \\
Deep strategy & $16.52 \pm 3.65$ & $15.7 I \pm 3.81$ & $16.10 \pm 3.16$ & 0.086 & 0.500 & 0.583 \\
Surface motive & $10.94 \pm 3.74$ & $12.66 \pm 4.36$ & $11.86 \pm 3.50$ & $\mathbf{0 . 0 0 2}$ & 0.152 & 0.329 \\
Surface strategy & $13.31 \pm 3.65$ & $14.92 \pm 3.82$ & $14.28 \pm 3.14$ & $\mathbf{0 . 0 0 1}$ & 0.121 & 0.377 \\
\hline
\end{tabular}

Notes: Values shown in bold are statistically significant.

Abbreviations: R-SPQ-2F, Biggs's Revised Two-Factor Study Process Questionnaire; MBBS, bachelor of medicine, bachelor of surgery; BDS, bachelor of dental surgery; $\mathrm{SD}$, standard deviation.

compared, except on the parameter measuring surface motive $(P=0.013)$ where self-funded students had greater score than scholarship students (11.54 versus 10.11). Variation between the sexes was not found on study approach; both male and female students scored almost same on all the parameters observed. When the study approach was compared between two age groups of students ( $\leq 20$ versus $>20$ years), no significant difference was observed.

\section{Discussion}

We examined the psychometric properties of the R-SPQ-2F for its use among health science students of CMC, which was found to have overall acceptable Cronbach's alpha values for scale reliability. Although alpha values of main scale and subscales were found to be lower in this study than that of Biggs et al, ${ }^{4}$ and Siddiqui, ${ }^{9}$ the findings were still supportive and favor R-SPQ-2F use. Correlations between main scales and subscales of the questionnaire were comparable with other studies that used the same questionnaire for similar purposes. ${ }^{9,12}$

In this study, we also explored the study approaches among medical, dental, and nursing students in the beginning years of their health professional undergraduate study so that their motives and strategies of learning could be changed in an appropriate manner timely for future if they were found to be surface learners. The results revealed that the students predominantly had deep approach to learning and this was seen in various contexts.

Medical students were found to have significantly higher score on deep approach and its subscales compared to dental and nursing students. In contrast to medical students, dental and nursing students had higher score on surface approach and its subscales. However, no significant differences were observed on any of the scale and subscales between dental and nursing students. Thus, our study revealed that although, overall, students of different programs (medical, dental, and nursing) were found to be deep learners, there were significant differences among the students of different programs on individual scales and subscales. The highest score for deep approach by medical students compared to others in our study indicated that medical students were more intrinsically interested to maximize the meaning of the subject materials. The differences in the curriculum for different programs of study, assessment methods, feedback, and others might have influenced their level of deep approach to learning. The mean score for deep approach of medical students of CMC (33.26) is comparable to the mean score of medical students of the University of Colombo (29.2) and Harvard Medical School students at the Beth Israel Deaconess Medical Center (33.02). ${ }^{7,13}$

Table 4 Comparison of study approach between first- and second-year medical and dental students

\begin{tabular}{|c|c|c|c|c|c|c|}
\hline \multirow[t]{2}{*}{ Variable } & \multicolumn{3}{|c|}{ MBBS students } & \multicolumn{3}{|c|}{ BDS students } \\
\hline & $\begin{array}{l}\text { First year } \\
(\mathrm{N}=134)\end{array}$ & $\begin{array}{l}\text { Second year } \\
(N=120)\end{array}$ & $P$-value & $\begin{array}{l}\text { First year } \\
(\mathrm{N}=\mathbf{3 8})\end{array}$ & $\begin{array}{l}\text { Second year } \\
(N=42)\end{array}$ & $P$-value \\
\hline Deep approach & $34.63 \pm 6.51$ & $31.73 \pm 5.93$ & $<0.001$ & $33.47 \pm 6.73$ & $29.09 \pm 5.62$ & 0.002 \\
\hline Surface approach & $24.35 \pm 6.52$ & $24.14 \pm 6.60$ & 0.801 & $25.55 \pm 8.19$ & $29.34 \pm 6.25$ & 0.023 \\
\hline Deep motive & $|7.32 \pm 3.6|$ & $16.08 \pm 3.36$ & 0.005 & $17.05 \pm 3.75$ & $14.02 \pm 2.93$ & $<0.001$ \\
\hline Deep strategy & $|7.3| \pm 3.6 \mid$ & $15.65 \pm 3.50$ & $<0.00 \mathrm{I}$ & $16.42 \pm 4.04$ & $|5.07 \pm 3.5|$ & 0.114 \\
\hline Surface motive & $11.03 \pm 3.73$ & $10.83 \pm 3.76$ & 0.665 & $11.21 \pm 4.49$ & $13.97 \pm 3.84$ & 0.004 \\
\hline Surface strategy & $13.32 \pm 3.60$ & $|3.3| \pm 3.7 \mid$ & 0.993 & $14.34 \pm 4.33$ & $15.46 \pm 3.25$ & 0.195 \\
\hline
\end{tabular}

Notes: All data are shown as mean $\pm \mathrm{SD}$, with the exception of $P$-values. Values shown in bold are statistically significant.

Abbreviations: MBBS, bachelor of medicine, bachelor of surgery; BDS, bachelor of dental surgery. 
Table 5 Multiple comparisons (ANOVA) between MBBS, BDS, and nursing students to explore the differences in mean score of different study approach

\begin{tabular}{|c|c|c|c|c|c|}
\hline Variable & $\begin{array}{l}\text { Sum of } \\
\text { squares }\end{array}$ & $d f$ & $\begin{array}{l}\text { Mean } \\
\text { square }\end{array}$ & $\boldsymbol{F}$ & Significance \\
\hline \multicolumn{6}{|l|}{ Deep approach } \\
\hline Between groups & 331.838 & 2 & 165.919 & 4.204 & 0.016 \\
\hline Within groups & $14,563.7 \mid 9$ & 369 & 39.468 & & \\
\hline Total & $14,895.556$ & 371 & & & \\
\hline \multicolumn{6}{|l|}{ Surface approach } \\
\hline Between groups & 683.222 & 2 & 341.611 & 7.629 & 0.001 \\
\hline Within groups & $16,477.625$ & 368 & 44.776 & & \\
\hline Total & $17,160.846$ & 370 & & & \\
\hline \multicolumn{6}{|l|}{ Deep motive } \\
\hline Between groups & 145.245 & 2 & 72.623 & 5.881 & 0.003 \\
\hline Within groups & $4,556.583$ & 369 & 12.348 & & \\
\hline Total & $4,701.828$ & 371 & & & \\
\hline \multicolumn{6}{|l|}{ Deep strategy } \\
\hline Between groups & 42.175 & 2 & 21.088 & 1.588 & 0.206 \\
\hline Within groups & $4,899.274$ & 369 & | 3.277 & & \\
\hline Total & $4,941.449$ & 371 & & & \\
\hline \multicolumn{6}{|l|}{ Surface motive } \\
\hline Between groups & 189.363 & 2 & 94.682 & 6.352 & 0.002 \\
\hline Within groups & $5,500.344$ & 369 & 14.906 & & \\
\hline Total & $5,689.707$ & 371 & & & \\
\hline \multicolumn{6}{|l|}{ Surface strategy } \\
\hline Between groups & 167.120 & 2 & 83.560 & 6.293 & 0.002 \\
\hline Within groups & $4,886.529$ & 368 & 13.279 & & \\
\hline Total & $5,053.650$ & 370 & & & \\
\hline
\end{tabular}

Notes: The mean difference is significant at the 0.05 level. Values shown in bold are statistically significant.

Abbreviations: ANOVA, analysis of variance; MBBS, bachelor of medicine, bachelor of surgery; BDS, bachelor of dental surgery.

We also found significant differences in deep approach along with its motive and strategy subscales between first- and second-year medical students without significant change in their surface approach and its subscales. Surprisingly, first-year medical students scored higher in all these parameters than second-year students. The finding was alarming as it indicated that level of deep approach to learning among students after 1 academic year in medical school was getting lowered due to reduction in their intrinsic motivation and strategies adopted for deep learning. The result indicated that deep approach to learning though reduced has not completely switched over to surface approach. Most likely, this might be the critical time to intervene by the educator to motivate and facilitate the students to formulate the strategies, which allow learning to progress beyond mere knowledge acquisition to being a memorable and confidence boosting experience. Among the dental students, significant differences were observed in both deep and surface approach to learning and their motive subscale, while no significant difference was noted in strategy subscale for both the approaches. The significantly lower mean value for deep approach and higher mean value for surface approach among second-year compared to first-year dental students clearly indicated that learning approach of the students was shifting toward surface approach. Reduction in value for deep motive and increment of value of surface motive among those students reflect the cause (decreased level of intrinsic motivation) of paradigm shift toward surface learner who feared failure in examination. Our findings are similar to those of other studies. For instance, Premkumar et $\mathrm{al}^{14}$ found self-directed learning readiness scores among medical students decreased significantly at the end of 1 year; Samarakoon et $\mathrm{al}^{8}$ showed decline in value for deep approach among final-year medical students compared to first-year students, but the decrease was insignificant.

We speculate the following reasons for changes toward surface learning approach among the students of CMC.

- Conventional written examination conducted after completion of each organ system, which usually demands the recall of factual information rather than understanding the content.

- Lack of constructive feedback to students after the formative assessments.

- Failure to provide enough opportunities and time to students to pursue their own academic interest.

- Educator's lack of interest to diagnose the learning approach of students in a timely manner for corrective measures.

These views are in line with some of the previous studies related to influence of assessment, leaning culture, and environment on learning approach of students. Premkumar et $\mathrm{a}^{14}$ found both students and instructors agreed that the type of assessment influences the self-directed learning and examination focused on memorization deterred such learning approach. ${ }^{14}$ The opposite of what is intended by a university education, which is characterized by heavy workloads, instructional methodologies, and a strong emphasis on examinations, there is supporting evidence of increasingly use of lower cognitive level activities by most undergraduate students as they progress. ${ }^{15-17}$ Students' perception of heavy workload and inappropriate assessment persuade them toward a surface approach, while perceptions of good teaching persuade them toward deep approaches to study. ${ }^{18}$ Obtaining the feedback from students about the design and implementation of the learning environment will help educators identify what has worked and where improvements could be made in the future. ${ }^{18,19}$

A study by Kumar and Sethuraman ${ }^{20}$ has shown a significant positive correlation between high academic 
achievement and deep approach learners and a positive correlation between low academic achievement and surface learners. Therefore, different measures should be initiated immediately to encourage surface learners, which will prevent further deterioration, and the situation can be reverted for high academic achievement.

On comparison between self-funded and scholarshipawarded students, only significant difference was found in surface motive scale, which suggested that self-funded students were more motivated by the fear of failure in examination. Otherwise, similarity in remaining scales of learning approach in those two groups was found to be remarkable. In contrast, Johnson ${ }^{21}$ has reported that students from the distinct matriculate pools were found to have significant differences in learning styles. We also found no statistically significant differences on any of the scales on the basis of sex and age (below and above 20 years). Similar results have been obtained in other previous studies too. ${ }^{7,9,12}$ However, our finding in relation to age was contradictory to the study done by Lim and Morris, ${ }^{22}$ which revealed that the learners between 20 years or higher had significantly higher mean scores in perceived learning, learning application, and learning involvement than those who were between 18 and 19 years.

The comparative study of first- and second-year nursing students could not be done as they were posted in the community during the study period. The study approach and the academic achievement of the students who participated in the study was not correlated, which is the limitation of our study. The further exploration of this study would be the measurement of the magnitude of change in learning approach of individual students in each academic year to identify a subgroup of individuals who actually improved their deep approach scores and finding the associated factors. Similar studies can be done in other medical colleges of Nepal for the establishment of use of R-SPQ-2F among Nepalese health science students and generalization of result.

\section{Conclusion}

Our result concluded that the use of R-SPQ-2F to evaluate the learning approaches among our study population is acceptable. We used R-SPQ-2F among first- and second-year medical, dental, and nursing students of CMC and found that the students predominantly had deep approach to learning. The difference in learning approach among the participants was not found on basis of sex and age. The level of deep approach to learning among medical students was found to be significantly higher than among dental and nursing students. The findings of our study also suggested that the learning approach of the students was shifting progressively toward surface approach after completion of an academic year in medical school. The gradual change in learning approach of students should be monitored from the first to final year in a medical school so that corrective measures, if necessary, could be taken for high academic achievement.

\section{Acknowledgments}

We acknowledge the article "The Revised Two Factor Study Process Questionnaire: R-SPQ-2F” by John Biggs, David Kember, and Doris YP Leung that encourages use of the questionnaire for the evaluation of teaching and for genuine research purposes. ${ }^{4}$ We also accept that the copyright on the questionnaire is owned by John Biggs and David Kember. We are thankful to Mr Govinda Prasad Dungana for his support in analyzing the data. We express sincere thanks to Institutional Review Board of Chitwan Medical College and the students who voluntarily participated in this study. The authors advise that they received consent to use the images of all of the students from Chitwan Medical College who appear in the video abstract.

\section{Author contributions}

All the authors made substantial contributions to conception and design, acquisition of data, and analysis and interpretation of data. They also contributed to drafting the article and revising it critically for important intellectual content, gave final approval of the version to be published, and agree to be accountable for all aspects of the work.

\section{Disclosure}

This research work has not been funded by the Chitwan Medical College or any other private/government organization. The authors report no conflicts of interest in this work.

\section{References}

1. Markwell D. Improving teaching and learning in universities. Business/ Higher Education Round Table. B-Hert News. November 2003; issue 18 .

2. Gordon C, Debus R. Developing deep learning approaches and personal teaching efficacy within a preservice teacher education context. BrJEduc Psychol. 2002;72:483-511.

3. Evans CJ, Kirby JR, Fabrigar LR. Approaches to learning, need for cognition, and strategic flexibility among university students. Br JEduc Psychol. 2003;73:507-528.

4. Biggs JB, Kember D, Leung DYP. The revised two factor study process questionnaire: R-SPQ-2F. Br J Educ Psychol. 2001;71:133-149.

5. Dart BC, Clark JA. Helping students become better learners: a case study in teacher education. High Educ. 1991;22:317-335.

6. Shreemathi Y. Learning Approaches of Health Profession Students: A Study of Undergraduate Medical Students of Manipal Academy of Higher Education [dissertation]. Manipal, Karnataka: Manipal Academy of Higher Education; 2001. 
7. Subasinghe SDLP, Wanniachchi DN. Approach to learning and the academic performance of a group of medical students - any correlation? Stud Med J. 2009;3(1):5-10.

8. Samarakoon L, Fernando T, Rodrigo C, Rajapakse S. Learning styles and approaches to learning among medical undergraduates and postgraduates. BMC Med Educ. 2013;13(42):1-6.

9. Siddiqui ZS. Study approaches of students in Pakistan: the revised two-factor study process questionnaire experience. Proceedings of the Conference on Teaching and Learning in Higher Education [Occasional Report 1]. Islamabad, Pakistan: Pakistan National Academy of Higher Education; 2006.

10. Gijbels D, Watering G Van de, Dochy F, Bossche P Van den. The relationship between students' approaches to learning and the assessment of learning outcomes. Eur J Psychol Educ. 2005;20(4):327-341.

11. Goh PSC. Perceptions of Learning Environments, Learning Approaches, and Learning Outcomes: A Study of Private Higher Education Students in Malaysia from Twinning Programmes [dissertation]. Adelaide, SA: University of Adelaide; 2005.

12. Taher AMM, Jin C. Assessing learning approaches of Chinese local MBA students: an investigation using the Revised Two-factor Study Process Questionnaire (R-SPQ-2F). Educ Res Rev. 2011;6(19):974-978.

13. Richards JB, Litman J, Roberts DH. Performance characteristics of measurement instruments of epistemic curiosity in third-year medical students. Med Sci Educ. 2013;23(3):355-363.

14. Premkumar K, Pahwa P, Banerjee A, Baptiste K, Bhatt H, Lim HJ. Does medical training promote or deter self-directed learning? A longitudinal mixed-method study. Acad Med. 2013;88:1754-1764.
15. Gow L, Kember D. Does higher education promote independent learning? High Educ. 1990;19:307-322.

16. Busato VV, Prins FJ, Elshout JJ, Hamaker C. The relation between learning styles, the Big Five personality traits and achievement motivation in higher education. Pers Indiv Diff. 1999;26:129-140.

17. Zeegers P. Approaches to learning in science: a longitudinal study. Br J Educ Psychol. 2001;71(1):115-132.

18. Lizzio A, Wilson K, Simons R. University students' perceptions of the learning environment and academic outcomes: implications for theory and practice. Stud High Educ. 2002;27(1):27-52.

19. Veerapen K, McAleer S. Students' perception of the learning environment in a distributed medical programme. Med Educ Online. 2010;15:5168.

20. Kumar LR, Sethuraman KR. Learning approaches in dental and medical students in AIMST: a comparison between deep and surface approaches. Paper presented at: The International Medical Education Conference, April 20-21, 2007, Kuala Lumpur, Malaysia.

21. Johnson M. Evaluation of learning style for first year medical students IJ-SoTL. 2009;3(1):Article 20.

22. Lim DH, Morris ML. Learner and instructional factors influencing learning outcomes within a blended learning environment. Educ Technol Soc. 2009; 12(4):282-293.
Advances in Medical Education and Practice

\section{Publish your work in this journal}

Advances in Medical Education and Practice is an international, peerreviewed, open access journal that aims to present and publish research on Medical Education covering medical, dental, nursing and allied health care professional education. The journal covers undergraduate education, postgraduate training and continuing medical education

\section{Dovepress}

including emerging trends and innovative models linking education, research, and health care services. The manuscript management system is completely online and includes a very quick and fair peer-review system. Visit http://www.dovepress.com/testimonials.php to read real quotes from published authors.

Submit your manuscript here: http://www.dovepress.com/advances-in-medical-education-and-practice-journal 